\title{
THE POWER OF LEAN PRINCIPLES
}

\author{
John Skaar ${ }^{1}$
}

\begin{abstract}
This article supports previous publications on the importance of lean principles as guidelines (Liker, 2004) or as challengers when developing systems and frameworks (Ballard, Hammond, \& Nickerson, 2009) and even methods and tools (Santos, 1999). It seems that the principles have taken the position of being a significant part of lean thinking, meaning a knowledge that lean personnel should acquire. This article wants to support and emphasise the importance of lean principles as rules of living but believes in taking the power of the lean principles one step further. If a lean organisation, project or leader explicitly confronts each other with the principles, this empowers the individuals being challenged and may create an outcome that closely links the employee's know-how to the process. Using lean principles as the main message to be understood, they may pull in tools, methods, frameworks or systems to answer these principles. This paper reports from research that explores the effect of pushing lean principles as the direct challenger on employees. Skilled workers at construction sites are the receiver of both general principles but mainly rephrased into more operational language.
\end{abstract}

\section{KEYWORDS}

Principles, philosophy, continuous improvement, action research, waste.

\section{INTRODUCTION}

"A principle describes the pathway to transform existing reality through the basic idea set by a concept"(Santos, 1999), this definition is used throughout this paper and shows the close link a lean principle has to a lean concept.

Lean leaders should apply, understand and use lean principles daily to increase their probability to succeed with lean implementation (Emiliani \& Emiliani, 2013). There are several papers within IGLC;

- Addressing the strategic issues of lean construction and the importance of organisational awareness towards lean principles (Almeida \& Salazar, 2003; Neto, 2002),

- Make principles a strategic toll/managerial method (Bertelsen \& Bonke, 2011)

- Addresses the need for tailoring the principles based on what type of situation in which they are used (Ballard et al., 2009; Ballard \& Howell, 1998).

- Papers are presenting the lean principles as suitable in measuring lean conformance (Diekmann, Balonick, Krewedl, \& Troendle, 2003) and structure implementation of lean (Picchi \& Granja, 2004).

1 Assistant Professor, Faculty of Engineering and Science, Department of Engineering Sciences, Univ. of Agder, Norway, + 4791909 313, john.skaar@uia.no 
- Bertelsen and Koskela advise how to operationalise TFV theory (Bertelsen \& Koskela, 2002)

There is also research addressing additional potential in implementing the lean principles in organisations (Coetzee, Van Der Merwe, \& Van Dyk, 2016).

This paper builds on these papers and wants to support the importance of leader's ownership of the principles but also wants to express a warning if a leader's conviction results in pushing the proclaimed lean tools and methods towards the employees.

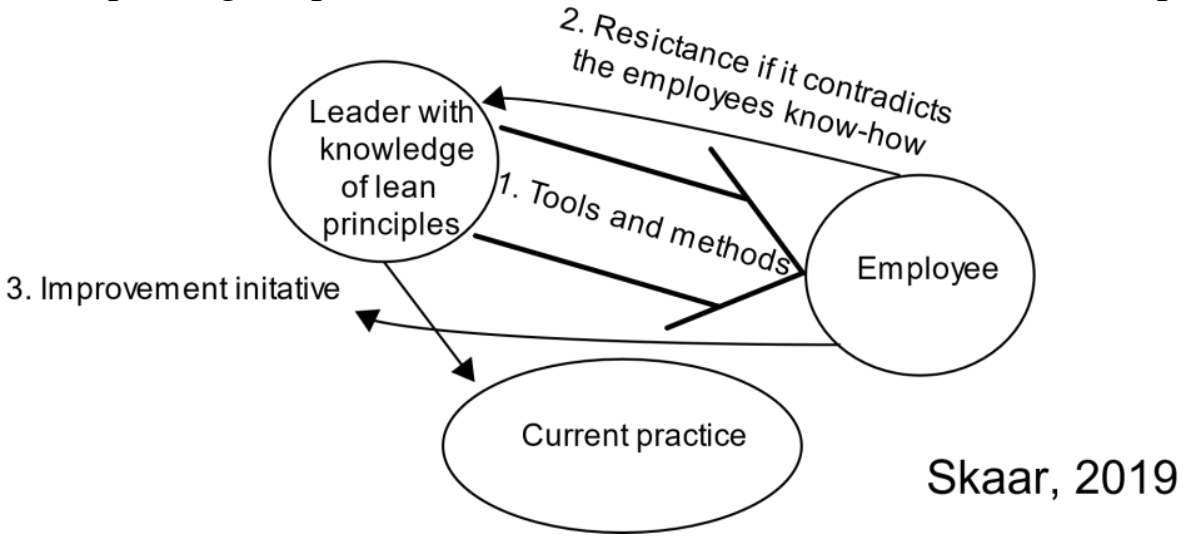

Figure 1 A leader with a lean mindset, pushes tools and methods on employees, may unintentionally submit the mean as the goal.

The reason for this warning is threefold:

1. The employee may not understand that the tool and method presented is just a mean toward a goal, and not the goal itself. Misinterpretation of the purpose might make the organisation more vulnerable to changes and needed system adjustments and negatively affect how an organisation both implement and measures the status of lean, especially if lean thinking is lacking among management (Howell \& Ballard, 1998).

2. A situation may occur where the tool and method presented by the leader shouldn't be prioritised for implementation because more prevailed problems exist in the current practice. The leaders lack of know-how can both discharge the leader's recognition and/or hurt the current practice. A point is underpinned by research supporting that a lean leader should be process-oriented, rather than result-oriented (Liker, 2004; Liker \& Convis, 2012; Rother, 2010). Are many lean leaders resultoriented in their eagerness to have tools and methods implemented, rather than being patient enough to have sufficient feedback loops with their employees?

3. If the employee resists the change (Porwal, Fernández-Solis, Lavy, \& Rybkowski, 2010) required from the leader, may or may not be a result of reasoned conflict with the current know-how. Nevertheless, it should be taken seriously as respect for the employee's experience and situation (Liker, 2004). 


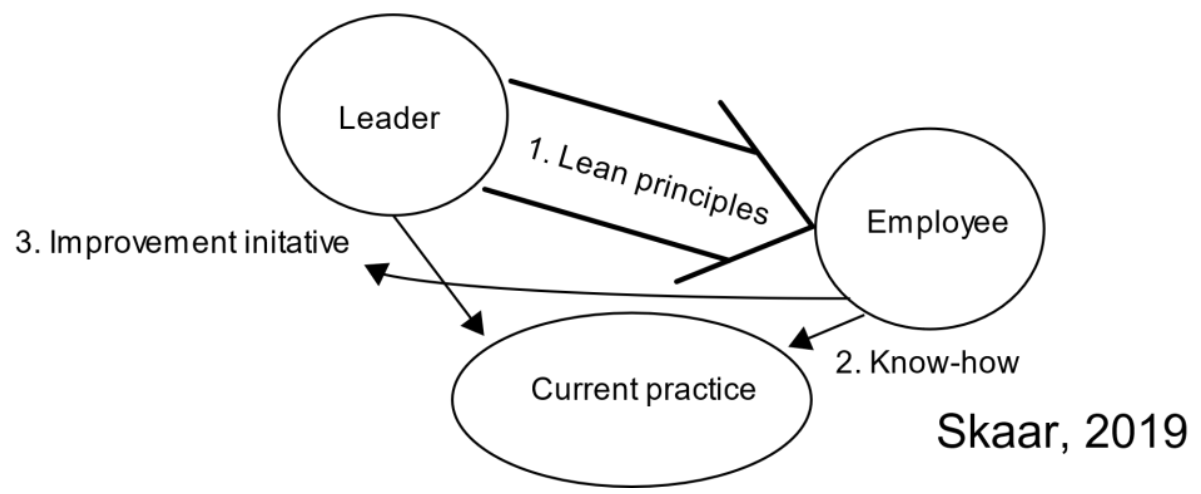

Figure 2 A lean leader pushing the principles towards the employee, may enable the employee to understand the lean mindset directly.

The reasoning behind using principles directly can also be summoned threefold:

1. A lean principle may spur lean thinking on its own, and consequently, the employee will be able to adapt their behaviour according to lean in changing and new contexts. In other words, enabling the employee to develop a lean mindset on their own (Howell \& Ballard, 1998).

2. A leader may avoid pushing a wrong or have the wrong timing of a solution if the employee gets the first opportunity to initiate countermeasures to a problem (Harford, 2011). With a present leader, the improvement initiatives can be discussed in order to make sure it complies with tactical and strategic decisions and organisational standards (Liker \& Convis, 2012).

3. Making the principles to be the spoken carriers of the lean culture, might empower the whole organisation to have a more innovative, flexible and agile approach to lean.

A point grounded in the effect of trust building (Smith, Rybkowski, Bergman, \& Shepley, 2014) and empowerment (Harley, 1995).

Literature has shown the importance of lean leaders to understand lean thinking (Howell \& Ballard, 1998), but why stop with the leaders? In a project-based industry with many different actors, getting the leaders to think lean is a challenge; everyone else involved even so. But if the goal is to develop a lean mindset, why not challenge the employees with what has been created to present the core of lean thinking, namely the lean principles? This paper wants to explore the effect of exposing lean principles directly towards the employee, and we start with the skilled workers.

The reason for starting with the skilled worker is twofold;

1. Regarding the skilled worker as the value creators in production (Liker \& Convis, 2012) and the rest of the organisation, if not directly creating value to the customer should serve the value creators (Goldratt, 2004). This way of seeing an organisation might be useful in reducing waste. This research adopts this view and puts the skilled worker as the starting point and "reverses" the research by going up the organisational line. Also inspired by the lean terms" Bottom-up" and "Go to Gemba" (Liker \& Convis, 2012). 
2. The research also builds on the assumption that the leaders in an organisation are more used to analytical processing in their line of work. It might be more challenging for the skilled worker to answer the lean principles, so an effect here might be more convincing.

\section{METHODS}

This paper's research view has a critical realism stand (Bhaskar, 2013). Thereby the epistemic fallacy (Bhaskar, 2013) is a core viewpoint. The epistemological (our study of knowledge) position might not be conceived to be relevant for practitioners and some academics but is essential for how we view the world and research, and thereby the methods the researchers use. Exploring fundamental views might lead to more in-depth knowledge also within lean construction as shown in previous work within Metaphysics (Our study of reality) of Koskela and Kagioglou (Koskela \& Kagioglou, 2005, 2006).

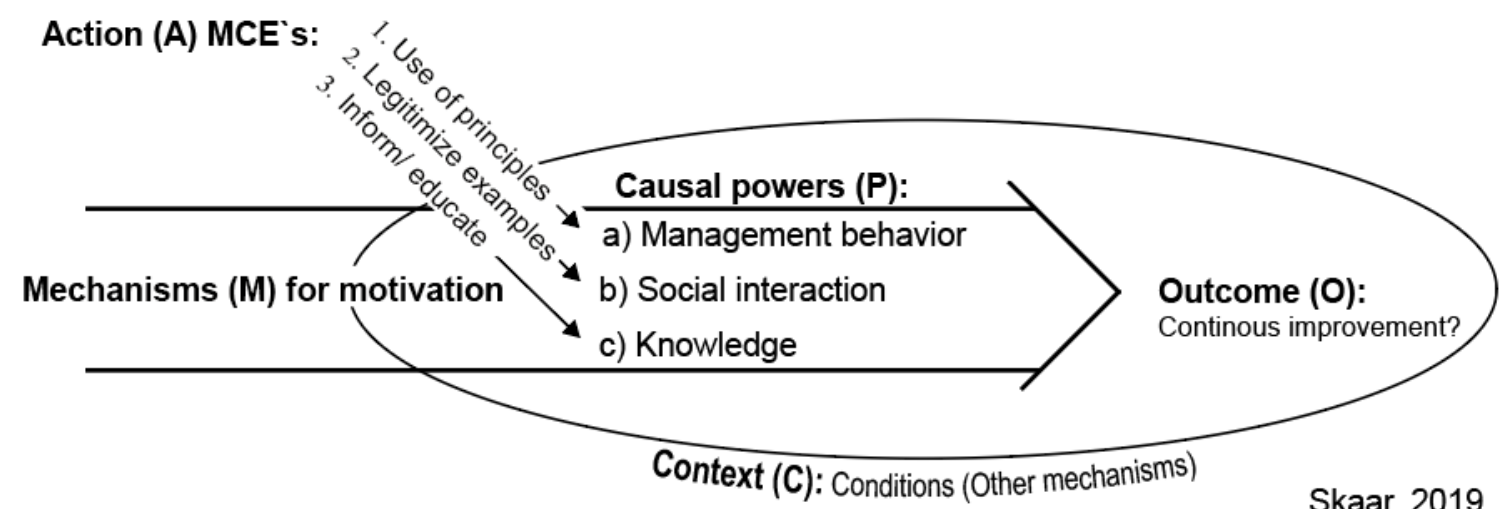

Figure 3 Methodology framework with stimulation of lean principles.

The underlying logic in figure 3 is from Ackroyd's Figure 6.1 "Realist explanation" in (Fleetwood \& Ackroyd, 2004). The basis of this figure is that a critical realist imposes action (A) believed to affect an underlying mechanism (M) and seeks for causality linked to the outcome (O) (Fleetwood \& Ackroyd, 2004). The study sees "motivation" as a complex mechanism, and we have defined motivation to "be moved to do something" (Ryan \& Deci, 2000).

This paper link three assumed causal powers $(\mathrm{P})$ to be central for the mechanism of motivation or challenges (Porwal et al., 2010) and the creation of positive outcome regarding improvement initiatives, namely;

1. Management behaviour: Challenge: Lack of leadership (Porwal et al., 2010). Countermeasure: 1.Use lean principles.

2. Social interaction Challenge: Organizational inertia \& resistance to change (Porwal et al., 2010). Countermeasure: 2. Legitimize examples.

3. Knowledge: Challenge: Lack of training (Porwal et al., 2010), Countermeasure: 3. Inform/educate.

The researchers take an active role in testing and driving the principles in the project, so learnings from action-based research is relevant. The method has taken inspiration from 
Lean Startup (Ries, 2011) literature, but instead of Minimal Viable Products (MVP), we named it Minimal Causal Experiments (MCE).

\section{"Minimal Causal Experiments"}

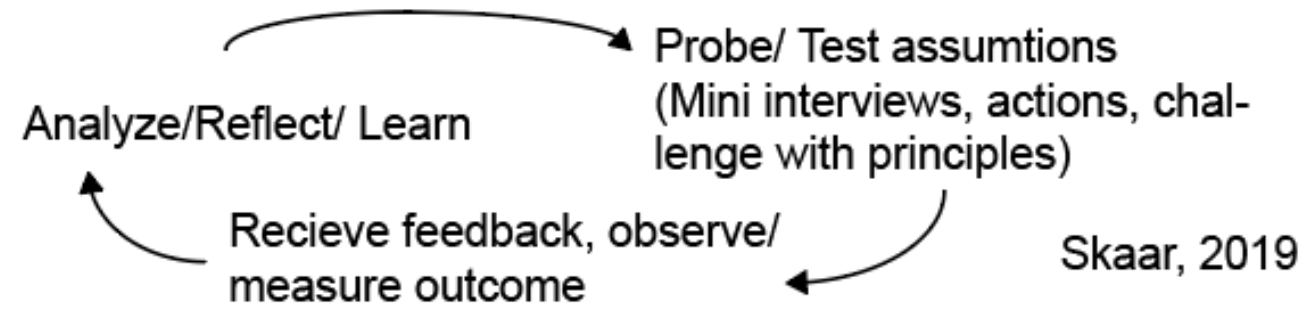

Figure 4 Inspired by Lean Startups "Minimal Viable Product" (MVP), the researchers conducted a learning loop named, "Minimal Causal Experiments" (MCE).

The loop visualised in figure 4 can be iterated many times during every encounter at the site. With the possibility to do a high pace of experiments, we can both gather information as from a traditional interview, but also directly educate, inspire and use principles in the field to spur the desired outcomes.

Alignment of interest between a research team and an organisation with lean ambitions gives unique possibilities to work together in a win-win situation. We learn from the obstacles and breakthroughs in the outcomes, and the organisations we research; get the improvements, more lean-educated personnel and hopefully a lean work mindset.

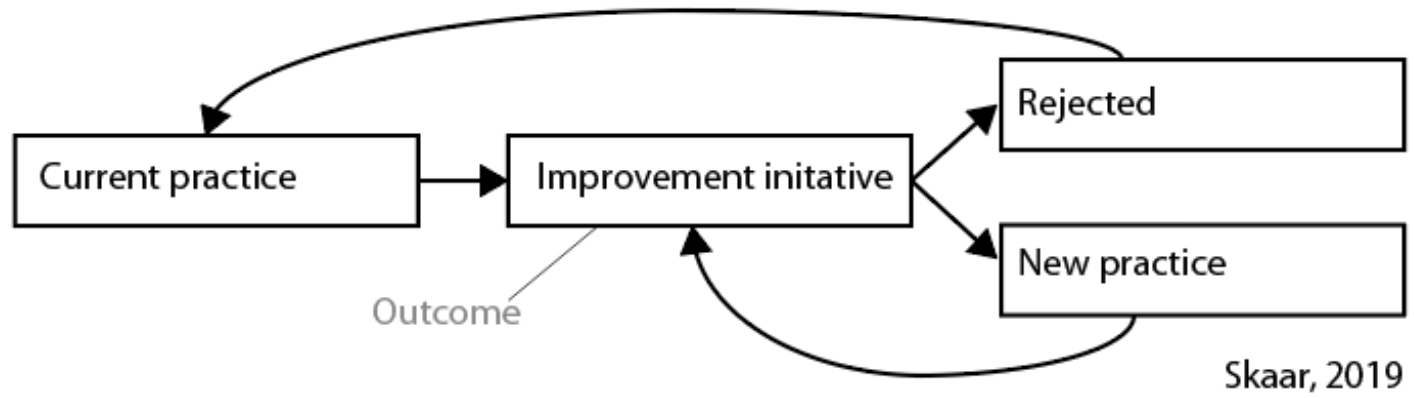

Figure 5 Any improvement initiative equals a desirable outcome

In short, we seek a deeper understanding of the actions giving tendencies in the mechanisms, the causal powers and the conditions spurring continuous improvement. Specifically, this paper seeks an understanding of whether a lean principle-based approach can be related to the preferred outcome.

This paper does not probe to distinguish between whether a person is intrinsic or extrinsically motivated (Ryan \& Deci, 2000), though we note reflections and ask for their type of motivation. The research links findings to different models of social interaction and learning. The research relates the observation toward Kolbs (Holman, Pavlica, \& Thorpe, 1997; Kolb, 1984), Illeris (Kalsaas, 2012), Bhaskar (Bhaskar, 2013) and Wilber (Bhaskar, 
Esbjörn-Hargens, Hedlund, \& Hartwig, 2015) but the collected data is still insufficient for claiming contribution to these areas.

There are four construction projects involved with different case studies (Easton, 2010), supported by three master thesis and one bachelor thesis, with a total of 8 students, all linked to the start of a PhD study done by the author. This paper refers mainly to 3 of the projects where the project management actively stated and used the rephrased principles in their organisation.

\section{FINDINGS AND DISCUSSION}

The research focused on rephrased principles supporting flow, note that the rephrased principles only supports part of the potential within the more general principle. The list therefore not to be considered exhaustively.

\begin{tabular}{|c|c|}
\hline General principle & $\begin{array}{l}\text { The rephrased principles asked directly to the } \\
\text { skilled workers. }\end{array}$ \\
\hline Create Flow & $\begin{array}{l}\text { - "Reduce (your) movement" } 1,2 \\
\text { - "Everything should have its place" } 1 \\
\text { - "Everything should be mobile" }{ }^{2} \\
\text { - "Everything on wheels" } 2 \\
\text { - "Never go empty handed" } 1 \\
\text { - "One piece flow" } 3\end{array}$ \\
\hline
\end{tabular}

The notation 1-3 behind the principles show how they were distributed over 3 individual projects. In the fourth project, the principles were not expressed to the skilled workers.

Examples of observations done with some of the rephrased principles follows:

\section{Challenging WiTh "EVERYThing ON WHEels".}

The observations below, are done by the author in a previous project that had weekly management rounds emphasising the principle "everything on wheels", and gave inspiration to the effect of rephrased principles;

1. One reaction was that the principle triggered solutions that gave easy moving of storage and workplaces from different locations and reduced unproductive time leaving and entering new areas (equality to SMED in production).

2. Another effect observed was that the workstation is rigged closer to the worker when doing work tasks; this seems to reduce the internal movement within the task process.

3. It also reduced the time spent clearing the area if another trade needed the space it occupied.

4. There were indications that a side effect of this principle was that employees kept the pathways tidy, motivated by increasing the mobility of the trolleys.

5. After a while, a "project culture" trying to answer the principle started to arise. It was indications that they repeatedly had to be nurtured by concise management that gave signals that they were not to abandon these principles; hence it became an expectation for everyone in the project. 

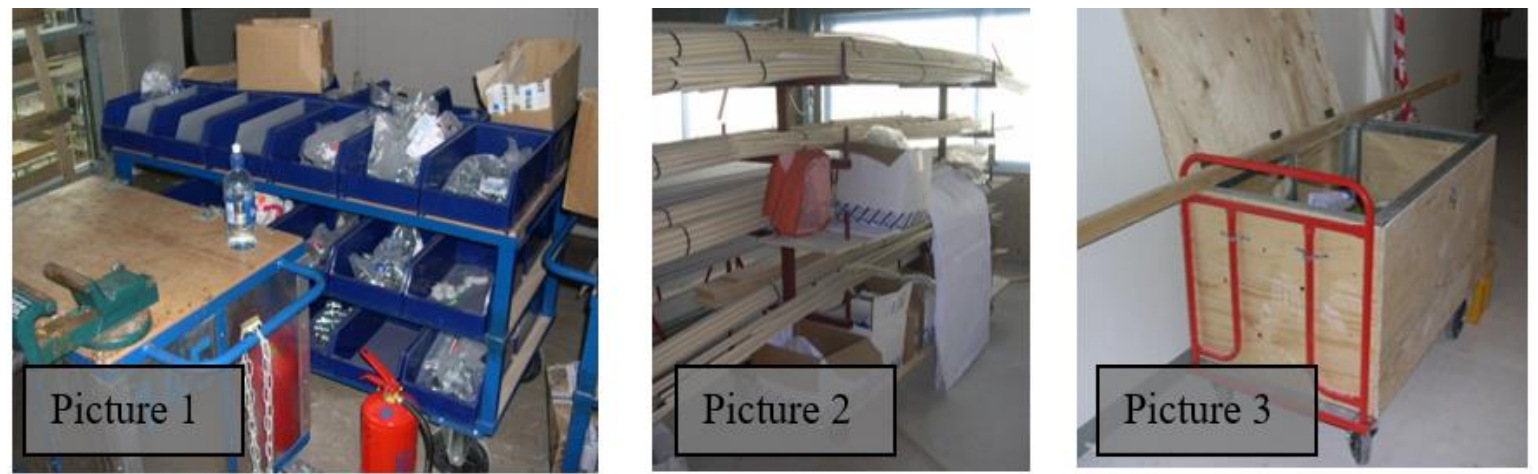

Figure 6 Examples from a project that challenged with the principle "everything on wheels". Picture 1 Both workstation and part storage, picture 2 Larger trolleys used for electrical tubes, metal stud and mouldings. Picture 3. More standard solution. (Photo: J.S)

\section{Challenging With "Reduce MOVEment." AND "EVERYTHING SHOUld HAVE ITS PLACE."}

One of the projects in the research emphasised the two rephrased principles "everything should have its place." and "reduce movement." The management on the project added "never walk empty-handed." A selected team leader was quick to understand the intention of principle-based improvements. The management conducted a mixed leadership by giving orders to effectuate results and a more challenging/ stimulating approach. Some examples of the results are below:
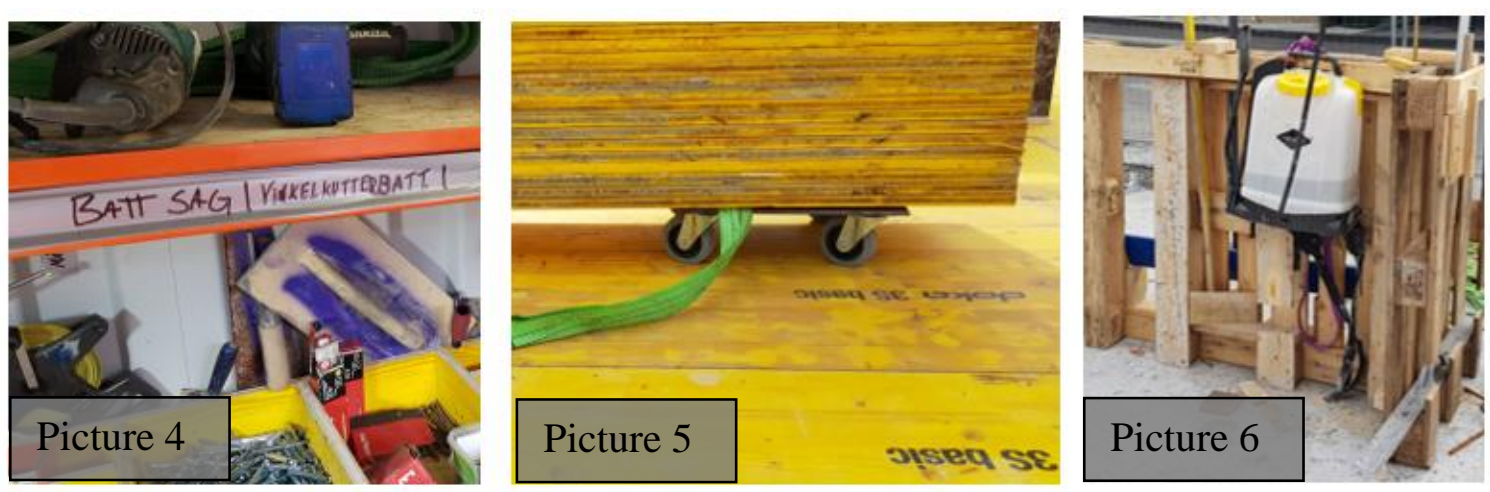

Figure 7 Picture 4: Inside a tool container, picture 5: A transport trolley and picture 6: A portable tool station. (Photo: J.Skaar)

Picture 4: The tool containers became an example, where continuous iterations took place within the containers but where the practice also spread to other teams.

Picture 5: A transport trolley was made to reduce the walking distance from primary storage to a moving workplace. But this became an example were further improvements to the trolley was acknowledged, but not effectuated.

Picture 6: A tool rack, as an answer to both principles, but at the same time an example of simplified solutions that still needed improvements to reach mandatory HSE standards. 


\section{A SUMMARY OF FINDINGS WITH DISCUSSION}

After conducting a series of rapid interviews on randomly selected skilled workers, as a part of the "MCE approach", the following observations came as a result:

- Almost all workers reported that they had heard about the "campaign".

- It seems that rephrased principles are easy to understand.

- Many senior workers are already using "waste reduction" as a way of thinking, but even though they acknowledge a potential towards perfection, they seem satisfied with their current perception.

- Young workers need more exemplification than many senior workers, but at the same time, they appear to be more open to several iterations, with a possible link to that their actual improvement potential is more considerable for them also.

- After the first improvement initiatives, there is an indication that the creativity stops, there are therefore indications that many rephrased principles must be available to generate continuous improvement and the leaders need to follow-up progress and initiatives carefully.

- Around 50\% of the improvement suggestions were suggestions outside the worker's area of direct influence.

- Work tasks with low frequency, are less motivational to improve than tasks done more frequently.

Some workers expressed a hostile or indifferent attitude against the use of principles. As a result, we did several "MCE" iterations around these attitudes to find the source of the attitudes expressed. Some of the findings follows:

1. Some of the hostile attituded was traced down to a "change in rules": As a part of "everything should have its place", all site containers had received their own "tagging colour", so that "yellow tagged tools, belongs to the yellow container". One of the teams reported that this had become a problem from them since their newly arrived container lacked necessary tools and when they tried to take equipment from others, they started to stress them more than usual.

In our opinion this is a positive effect, as in the Japanese sea, "lowering the water, to reveal the rocks". The problem with their lack of tools became an issue, instead of hiding it by just taking from other containers and cause ripple effects in unproductive search for equipment.

2. A negative attitude could also be traced down to misunderstandings on the actual use of principles. One interpretation conceived the principle to be an order to "tidy their containers". When confronted with the information that the principles were meant to challenge and try to reduce their movements, one first reaction was "isn't movement good for our health?" Our respond made us reflect on the importance of emphasising that it is waste movements we want to reduce, not necessarily the the total amount.

Our reflection then became threefold. The information about how to think, differ from person to person, so management rounds might be an effective method to adjust some interpretations along the way. The intention of the principle is not always understood even 
if it produces some positive outcome. And finally, emphasising that the goal is for them to become more efficient without "running faster" is still relevant.

3. Some of the workers already use a way of thinking in their line of work comparable to the lean rephrased principles. Observing some smart working routines, made the need for an effective way to spread good ideas evident.

We observe that the first iterations with a rephrased principle often felt natural for the worker to do. We then observed more resistance when trying to improve the solution from the first iteration. The researchers reflected on that it's when you do several iterations, the less obvious potential of continuous improvement reveals itself. Being persistence within one lean principle may teach the scrutinises of lean.

\section{LIMITATIONS AND FURTHER RESEARCH}

The number of projects, interviews and "Minimal Causal Experiments" (MCE) are still low to draw strong causal links from the action. The use of MCE generates an active role as a researcher, that even talks on behalf of the management. A researcher that speaks on behalf of a manager alters a lot of the conditions in the situation we want to simulate. We defend the researcher's active role by the fact that it still is a more genuine situation than an answer on a survey. To get stronger tendencies, we believe we need to continue the fieldwork.

Focusing on only a few of all the lean principles, may limit the picture since it does not contain all aspects of improvement and hence give wrong prioritizations. Using a method for prioritising the most paramount principle are in order.

For further research, we are especially interested in seeking if positive feedback and recognition of a good attempt of improvement stimulate the repetitiveness of improvement initiatives. The use and form of visualisation in spreading new practices and supporting the process is also an exciting topic. At the same time, we have many different rephrased principles to test.

Regarding framework and methodology, can MCE rounds be useful both for researchers and managers to learn and educate the organisation on the use of principlebased management? How are our MCE rounds, inspired by Lean Startup (Ries, 2011), compared to methods reportedly used by management in Toyota like the "Ohno circle" (Liker \& Convis, 2012) and "Toyota Kata" (Rother, 2010)?

This research is starting on an operational level to understand more about the mechanisms and actions to stimulate the powers for the desirable outcome and continue the approach up through the tactical level and up to strategic level. To be able to find a suiting lean framework for management in construction, it is natural to look towards Hoshin Kanri (Liker \& Convis, 2012), but at the same time, this research wants to challenge it with more active use of lean principles and see how and where digitalisation can support the framework. The effects of a framework like this are still to be tested.

If lean tools and methods are pulled in from the use of principles, rather than pushed and whether the intrinsic motivation increases is still an assumption that needs more data to find stronger tendencies of causality. We hope that further research can create a much more 
self-driven culture on improvements after exposing projects more consistently with lean principles.

The case study has been conducted in Norway, a country where skilled workers are known for being independent and have a high level of training and education. The respect for skilled workers in Norway is also high, so the general culture on Norwegian construction sites is a part of the context.

\section{CONCLUSION}

We find causalities that challenging skilled workers directly with principles create motivation for the use of principles. Our initial assumption that rephrased principles give more direct outcome than general principles are also strengthened in this research. Rephrased principles have a shorter lifespan, in the sense that they are more specified. Rephrased principles need either be bundled or be replaced by other principles at a higher frequency than more general principles to reach over the same area of potential.

From the research, we can see tendencies that the skilled workers translate the rephrased principles into their working situation, with limited need for explaining. They often need some guidance to translate the more general lean principles, but the advantage of these is that they are less specific, and hence can be used in more situations. Still, it's a tendency that the level of motivation is stronger with the rephrased principles, so at least as an introduction to active use of lean principles, rephrased principles are an interesting mean.

\section{REFERENCES}

Almeida, J. C., \& Salazar, G. F. (2003, 2003/01/01). Strategic Issues in Lean Construction. Paper presented at the 11th Annual Conference of the International Group for Lean Construction, Virginia, USA.

Ballard, G., Hammond, J., \& Nickerson, R. (2009, 2009/07/15). Production Control Principles. Paper presented at the 17th Annual Conference of the International Group for Lean Construction, Taipei, Taiwan.

Ballard, G., \& Howell, G. (1998, 1998/08/13). What Kind of Production Is Construction? Paper presented at the 6th Annual Conference of the International Group for Lean Construction, Guarujá, Brazil.

Bertelsen, S., \& Bonke, S. (2011, 2011/07/13). Transformation-Flow-Value as a Strategic Tool in Project Production. Paper presented at the 19th Annual Conference of the International Group for Lean Construction, Lima, Peru.

Bertelsen, S., \& Koskela, L. (2002, 2002/08/06). Managing the Three Aspects of Production in Construction. Paper presented at the 10th Annual Conference of the International Group for Lean Construction, Gramado, Brazil.

Bhaskar, R. (2013). A Realist Theory of Science: Taylor \& Francis.

Bhaskar, R., Esbjörn-Hargens, S., Hedlund, N., \& Hartwig, M. (2015). Metatheory for the Twenty-First Century: Critical Realism and Integral Theory in Dialogue: Taylor \& Francis. 
Coetzee, R., Van Der Merwe, K., \& Van Dyk, L. (2016). Lean implementation strategies: how are the Toyota way principles addressed? South African Journal of Industrial Engineering, 27(3), 79-91. doi:10.7166/27-3-1641

Diekmann, J. E., Balonick, J., Krewedl, M., \& Troendle, L. (2003, 2003/01/01). Measuring Lean Conformance. Paper presented at the 11th Annual Conference of the International Group for Lean Construction, Virginia, USA.

Easton, G. (2010). Critical realism in case study research. Industrial Marketing Management, $39(1)$, 118-128. doi:https://doi.org/10.1016/j.indmarman.2008.06.004

Emiliani, M., \& Emiliani, M. L. (2013). Music as a framework to better understand Lean leadership. Leadership \& Organization Development Journal, 34(5).

Fleetwood, S., \& Ackroyd, S. (2004). Critical realist applications in organisation and management studies. London: Routledge.

Goldratt, E. M. (2004). The goal : a process of ongoing improvement: Third revised edition, twentieth anniversary edition. Great Barrington, MA : North River Press, [2004] (C)2004.

Harford, T. (2011). Adapt: Why Success Always Starts with Failure: Farrar, Straus and Giroux.

Harley, W. B. (1995). Eight critical principles of empowerment. Empowerment in Organizations, 3(1), 5-12. doi:10.1108/09684899510079771

Holman, D., Pavlica, K., \& Thorpe, R. (1997). Rethinking Kolb's Theory of Experiential Learning in Management Education: The Contribution of Social Constructionism and Activity Theory. Management Learning, 28(2), 135-148. doi:10.1177/1350507697282003

Howell, G., \& Ballard, G. (1998, 1998/08/13). Implementing Lean Construction: Understanding and Action. Paper presented at the 6th Annual Conference of the International Group for Lean Construction, Guarujá, Brazil.

Kalsaas, B. T. (2012). The Last Planner System Style of Planning: Its Basis in Learning Theory. Journal of Engineering, Project, and Production Management, 2(2), 88100. doi:10.32738/jeppm.201207.0005

Kolb, D. A. (1984). Experiential learning : experience as the source of learning and development. Englewood Cliffs, N.J: Prentice-Hall.

Koskela, L., \& Kagioglou, M. (2005, 2005/07/19). On the Metaphysics of Production. Paper presented at the 13th Annual Conference of the International Group for Lean Construction, Sydney, Australia.

Koskela, L., \& Kagioglou, M. (2006, 2006/01/01). On the Metaphysics of Management. Paper presented at the 14th Annual Conference of the International Group for Lean Construction, Santiago, Chile.

Liker, J. K. (2004). The Toyota way : 14 management principles from the world\&\#39; greatest manufacturer: New York : McGraw-Hill, [2004] (C2004.

Liker, J. K., \& Convis, G. L. (2012). The Toyota way to lean leadership : achieving and sustaining excellence through leadership development: Maidenhead : McGraw-Hill Professional. 
Neto, J. d. P. B. (2002, 2002/08/06). The Relantionship Between Strategy and Lean Construction. Paper presented at the 10th Annual Conference of the International Group for Lean Construction, Gramado, Brazil.

Picchi, F. A., \& Granja, A. D. (2004, 2004/08/03). Construction Sites: Using Lean Principles to Seek Broader Implementations. Paper presented at the 12th Annual Conference of the International Group for Lean Construction, Helsingør, Denmark.

Porwal, V., Fernández-Solís, J., Lavy, S., \& Rybkowski, Z. K. (2010, 2010/07/14). Last Planner System Implementation Challenges. Paper presented at the 18th Annual Conference of the International Group for Lean Construction, Haifa, Israel.

Ries, E. (2011). The lean startup : how today's entrepreneurs use continuous innovation to create radically successful businesses. New York: Crown Business.

Rother, M. (2010). Toyota kata : managing people for improvement, adaptiveness, and superior results. New York: McGraw Hill.

Ryan, R. M., \& Deci, E. L. (2000). Intrinsic and Extrinsic Motivations: Classic Definitions and New Directions. Contemporary Educational Psychology, 25(1), 54-67. doi:https://doi.org/10.1006/ceps.1999.1020

Santos, A. (1999). Application of flow principles in the production management of construction sites. (PhD), University of Salford, Retrieved from http://usir.salford.ac.uk/2231/

Smith, J. P., Rybkowski, Z. K., Bergman, M., \& Shepley, M. (2014, 2014/06/25). TrustBuilder: A First-Run Study on Active Trust-Building. Paper presented at the 22nd Annual Conference of the International Group for Lean Construction, Oslo, Norway. 